\title{
A new Leptodactylus and a new Nototrema from Brazil.
}

By

\section{LARS GABRIEL ANDERSSON}

With 2 Plates and 1 Figure in the Text.

Communicated May 10th by HJ. Théel and E. Lönnberg.

\section{Leptodactylus bufo n. sp.}

Plate 1.

Habit very stout. Tongue very broad, somewhat broader than long, circular, not nicked behind. Vomerine teeth in two arched series behind the large choanæ; a distinct transverse ridge on each side of the palate between the vomerine teeth and the margin of the jaw. Snout rounded, slightly prominent, $1 \frac{2}{3}$ the largest diameter of the orbit; nostril half-way between the eye and the tip of the snout; no canthus rostralis. Interorbital space a little narrower than the upper eye-lid. Tympanum nearly circular, $2 / 3$ the width of the orbit. Fingers moderate, free; the first much longer than second; on the first finger the tip is broad and rounded, on the others it is pointed; a spurlike tubercle on the inner side of the first finger. Toes long, not fringed, but with a low dermal ridge along the sides, as in some other large Leptodactylus-specimens; a rudiment of web at the bases; subarticular tubercles feeble, no outer metatarsal tubercle, an inner oval, not very prominent. The measurement of the length of tibia, marked off along the body forwards from the knee, 
reaches between the nostril and the tip of the snout. ${ }^{1}$ Skin on the back, on the sides, and on the upper parts of the hind limbs tulercular; on the back and on the hind limb the tubercles are small and scattered, on the sides large and partly fused together in irregular large warts. On each side of the back runs a narrow but distinct glandular fold from behind the eye to the outer end of the sacral vertebra; traces of such folds are also to be seen on the sides. The upper parts of the head and of the fore limbs, and the whole underside are perfectly smooth.

Brownish grey above with small black dots, especially on the tubercles and on the folds; the under surfaces of hand and foot blackish brown. All other parts: the sides of the body, the lips, the whole underside and concealed parts of limbs brownish black with large irregular white spots; on the belly, the under parts of thighs, and to some extent also on the sides, the white colour prevails, so that one may say that they are white with a network of blackish brown. No cross- bars on the limbs. Tympanum greyish brown with a broad dark margin.

The specimen is a male (no external vocal sacs). Measurements: Length from nose to vent $115 \mathrm{~mm}$, length from nose to hind margin of tympanum $42 \mathrm{~mm}$., length of nose $20,5 \mathrm{~mm}$. Diameter of orbit $11 \mathrm{~mm}$, diameter of tympanum $8 \mathrm{~mm}$; breadth of head at the angle of mouth $46 \mathrm{~mm}$. Length of fore limb (along the posterior surface) $67 \mathrm{~mm}$; length of femur $61 \mathrm{~mm}$, length of tibia $58 \mathrm{~mm}$, length of foot with 4:th toe $87 \mathrm{~mm}$.

On account of the great size and the large tympanum the species comes near to $L$. pentadactylus LaUR. but it differs distinctly from this one especially by the quite different appearence of the skin and by the colour. Nor can I find it identical with any species with dorsal folds.

1 The usual way of measuring the length of the hind limb in comparison with that of the body: "the hind limb being carried forwards along the body etc.", is here, as I have also found in many other cases, rather unsuitable, if one will not get the risk of breaking the tibia at the knee. I find it much better to mark off the length of the tibia with a pair of compasses, the limbs of the animal being pressed to the body in usual resting position as on the plate. It may not be difficult to place the limbs in this natural situation, and the measurement cannot then be taken in more than one manner, which is not always the case in the usual way of measuring. 
L. G. ANDERSSON, A NEW LEPTODACTYLUS, A NEW NOTOTREMA. 3

The specimen is collected by Dr P. Dusén, at Ponta Grosso, Paraná, Brazil, and belongs to the collections of the R. Museum of Natural History in Stockholm.

\section{Nototrema fulvorufa $n$. sp.}

Plate 2.

Tongue large, circular, nicked behind; vomerine teeth in two short, slightly curved series close to each other and on a level with the hind margin of the rather large choanæ. Head moderate; derm of head free from cranial ossification; snout rounded, longer than the diameter of eye; loreal region feebly concave; canthus rostralis distinct; interorbital space twice as broad as the upper eye-lid; nostril near the tip of the snout, its distance from the eye being as large as the orbital diameter. Tympanum half the diameter of eye; the anterior and lower part very distinct, the upper merging into the skin. A fold above the tympanum; the postocular region rather swollen.

Outer fingers with a very slight rudiment of web; first finger slightly longer than second; the disks on the 3:th and 4:th fingers as large as the tympanum, those on the 1:st and 2:nd fingers considerably smaller. Toes halfwebbed; on the $4:$ th toe the web is attached to the third distal joint, on the inner side at its base, on the outer side at its middle. The disks of toes as large as those of fingers; the three outer disks are considerably larger than the two inner. An inner oval metatarsal tubercle, no outer. The measurement of the length of tibia marked off along the body forwards from the knee, reaches the tip of the snout. ${ }^{1}$

Skin granular, but the inner sides of the fore limb and of the hand and the concealed parts of the hind limb smooth. The upper parts of the head, the back, and the sides minutely granular; on the back and on the sides there are numerous larger round granules between the small ones. On the extremities the granules are much less prominent, but also on these there are two kinds: numerous small and scattered larger ones. The chin, belly, and under parts of thighs coarsely granular.

\footnotetext{
${ }^{1}$ See above, the footnote on p. 2.
} 
The colour in spirit: Upper parts of head and body ochraceous brown with dark shades, under parts uniform reddish brown; legs pale yellow with broad distinct brown crossbands, bordered with black.

Measurements: Length from nose to vent $68 \mathrm{~mm}$; length of nose $11 \mathrm{~mm}$; diameter of orbit $7,5 \mathrm{~mm}$; diameter of tympanum $3,5 \mathrm{~mm}$; greatest breadth of head $24 \mathrm{~mm}$; smallest breadth of interorbital space $10,5 \mathrm{~mm}$; length of femur 33 $\mathrm{mm}$; length of tibia $35 \mathrm{~mm}$; length of tarsus with $4:$ th toe $48 \mathrm{~mm}$.

The specimen is captured near Santos, Prov. San Paulo, Brazil, by Mr HJalmar Mosin 1874, and belongs to the collections of the R. Museum of Natural History in Stockholm.

It is a female with small eggs in the ovary. Of the dorsal pouch, typical for the Nototrema-females, there is externally only a distinct dermal fold, bordering a longitudinal oval area on the posterior third part of the back. No opening to any cavity under the dorsal skin is to be seen, and if we did not know that a dorsal pouch is typical for the genus Nototrema, we would not be able to suspect any such, though the very loose, vide, and at the sides plicated skin speaks for a state of things that corresponds with other species. Cutting up the dorsal skin I also found a large wide pouch, reaching as far as to the head, though now quite empty. As usual it is enclosed by the dorsal skin and a thin membrane, distinctly separated from the underlying dorsal muscles and serving as floor in the pouch. Along the above mentioned fold the membrane is connected with the skin, the cavity thus being a completely closed up room (figure $1 \mathrm{c}$ ). In the bottom of the fold, where the skin even now is very thin, at the breeding season the thickened edge of the dorsal skin evidently loosens, the pouch getting an opening outwards (fig. $1 \mathrm{~d}$ ); probably at the same time the lateral folds, bordering the area spoken of above, grow towards each other, forming a kind of vestibulum to the large inner pouch with a fissure-like outer opening between the edges. Afterwards when the young ones have left the pouch, the folds sink in again towards the sides, the vestibulum disappears, and the opening to the inner pouch closes up, the free border growing together with the skin which lies behind. In other ways I at least cannot understand the 
structure of the pouch in this specimen where certainly no exterior opening exists on the large interior room.

D. F. Weinland, the first one who has described the pouch, seems to me to be right regarding its origin. He considers it to be a dermal invagination, whereby - I think - the upper leaf of the infolded skin grows together with the external dorsal skin (figure $1 \mathrm{a}, \mathrm{b}$ ). When the pouch is not in use, the two leaves grow together at the opening, separating again from each other $a t^{2}$ a

the next laying of eggs.

In a paper, Die Brutpflege der schwanzlosen $\mathrm{Ba}$ trachier in Abhandl. Naturf. Gesellsch. Halle Bd 22, 1901, Messrs. Brandes and Schoenichen are of quite another thought regarding the origin and metamorphosis of the pouch. They ground their meaning on the state of things in $\mathrm{No}$ totrema pygmaиm BовттGER, but seem to believe that a similar case exists in other forms as well. According to them the pouch should be formed in such

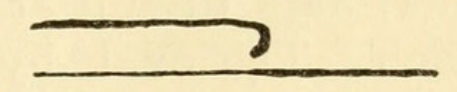

Figure 1. The inner dorsal pouch by Nototrema (schematic figures). $a$ and $b$ show different stages of the supposed development of the pouch; $c$ the pouch not in use; $d$ the pouch ready for use. b
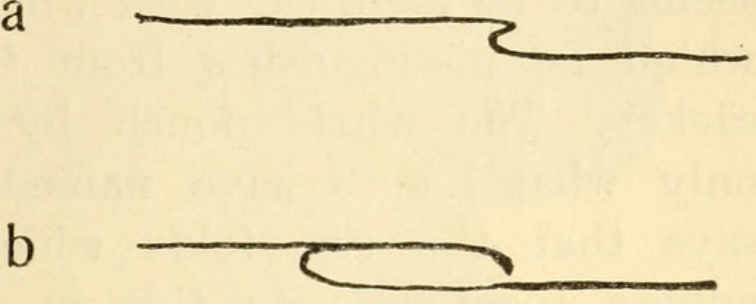

b

c

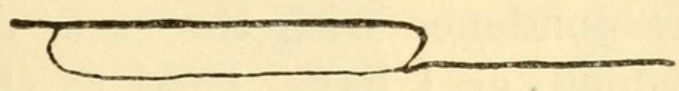

a way that a belt of thin skin arises on the median part of the back, gradually extending towards the sides, while at the same time the dorsal skin rises itself in two longitudinal lateral folds, gradually growing towards the middle where they melt together, leaving a small opening farthest back. In N. pygmoeum this suture should open again along its whole length, when the young-ones are ready to leave their nursery, whereupon the pouch completely disappears, being quite new-formed at the next breeding season.

This specimen shows that no resorbtion of the inner pouch has occurred, neither can it be any break in the median line at least in the Nototrema-forms in general, in which nothing speaks of such an origin and metamorphosis as Brandes and Schoenichen suppose. I also find that Ga- 
Dow in the Cambridge Natural History 1901 doubts such a break even in the Nototrema pygmoeum where, however, there is a long fissure along the back. Without any examination of a female of this form, preferably both with, and without eggs in the pouch, it is of course rather difficult to express an opinion on this matter and to understand the relation between this and the other species, but to judge by the figures of Brandes and Schoenichen the pouch in N. pygmoum seems to be identical with what WeInland names »Beutel», which he distinguishes from the inner pouch, »die Blindsäcke». The whole pouch by $N$. pygmoum should then be only what I here have named vestibulum. Also WeINLAND says that the two folds which border the »Beutel» may adhere together. By this way of explaining the pouch of $N$. pygmoeum its origin and metamorphsis, as it is described by Brandes and Schoenichen, should be rather well in correspondence with the state of things in the other species, in which, as I have tried to show with the help of this specimen, the outer part of the pouch, the vestibulum, originates from two low lateral dermal folds, which grow towards each other, and disappear again, when the young-ones leave the pouch. The oval, by low dermal ridges bordered area which in this and probably also in other species exist on the posterior part of the back, when the pouch is empty ${ }^{1}$, should then, if my opinion is right, reach over the entire back in Nototrema pygmoeum. The outer cavity (»vestibulum») which originates from it would then be sufficient for secreting the eggs, and there should not be any reason for an invagination of the skin to an inner large pouch, as in other forms, where the vestibulum is small.

This new species as well as Leptodactytus bufo are kindly revised by Dr. G. A. Boulenger, wherefore I beg to express to him my sincere gratitude.

${ }^{1}$ See Boulenger's figure of $N$. longipes in Cat. Batr. Sal. Pl. 27.

Tryckt den 7 juli 1911. 


\section{$2 \mathrm{BHL}$ Biodiversity Heritage Library}

Andersson, Lars Gabriel. 1911. "A new Leptodactylus and a new Nototrema from Brazil." Arkiv för zoologi 7, 1-6. https://doi.org/10.5962/bhl.part.1271.

View This Item Online: https://www.biodiversitylibrary.org/item/30233

DOI: https://doi.org/10.5962/bhl.part.1271

Permalink: https://www.biodiversitylibrary.org/partpdf/1271

\section{Holding Institution}

MBLWHOI Library

\section{Sponsored by}

MBLWHOI Library

\section{Copyright \& Reuse}

Copyright Status: NOT_IN_COPYRIGHT

This document was created from content at the Biodiversity Heritage Library, the world's largest open access digital library for biodiversity literature and archives. Visit BHL at https://www.biodiversitylibrary.org. 